\title{
Repensando la paz, la seguridad y la democracia en Nicaragua 25 años después de la guerra
}

Recibido: 10/11/2016 / Aprobado: 12/11/2016

Las interrogantes sobre el rumbo de la paz y la democracia en el país están tan vivas como a inicios de la década de los 90, entre ellas: ¿qué tan firme y duradera es la paz que hemos construido?, ¿qué cambios, en términos culturales y políticos, hemos experimentado como sociedad de posguerra?, ¿cuáles son los logros más importantes de este proceso?, ¿cuáles son las grandes dificultades?, ¿qué perspectivas se vislumbran para el futuro?, ¿qué retos están pendientes?

Con estas preguntas como guía y en conmemoración de los veinticinco años del fin de la guerra en Nicaragua, el Instituto de Estudios Estratégicos y Políticas Públicas (IEEPP), la Universidad Politécnica de Nicaragua (UPOLI), la Universidad Americana (UAM) y la Fundación Friedrich Ebert (FES), decidieron realizar un ciclo de conferencias que nos permitieran reflexionar colectivamente sobre el camino que hemos recorrido y los retos que nos esperan. Se realizaron nueve conferencias en tres universidades del país: la Universidad Americana (UAM), la Universidad Politécnica de Nicaragua (UPOLI) y la Bluefields Indian and Caribbean University (BICU) en la Costa Caribe. La primera conferencia estuvo a cargo del sociólogo y economista Oscar René Vargas, quien presentó su visión sobre el recorrido del país y los retos a futuro en la economía, la política y lo social. La segunda conferencia fue dictada por Mauricio Herdocia, uno de los más destacados juristas del país y partícipe de los procesos de negociación para conseguir la paz en Centroamérica.

La tercera conferencia estuvo a cargo del profesor Anastasio Lovo del Instituto Martin Luther
King de la UPOLI, quien analizó los avances y retos del país en la construcción de la paz. La cuarta conferencia estuvo a cargo de Elvira Cuadra, quien analizó la evolución de los conflictos en el país desde 1990 y los retos que representan para la construcción de la paz; la sexta conferencia fue impartida por Martha Cabrera y aborda uno de los aspectos más subestimados en las sociedades de posguerra: los duelos colectivos y las sanación de las heridas.

La séptima conferencia estuvo a cargo del filósofo y jurista, Alejandro Serrano, quien analizó los retos de la sociedad nicaragüense en materia de democracia, seguridad y paz a partir de su propuesta programática "La Nicaragua posible". La octava conferencia fue impartida por Alejandro Bonilla y se enfocó en el análisis de los procesos de saneamiento de las tierras propiedad de los grupos indígenas en Nicaragua; mientras que la novena conferencia estuvo a cargo de Elvira Cuadra y tuvo como propósito reflexionar con un grupo de jóvenes sobre los grandes retos de la construcción de la paz en Nicaragua, especialmente aquellos referidos a la democracia, la seguridad y el desarrollo.

Las diferentes conferencias y debates, pusieron de relieve que la paz, la seguridad y la democracia, son todavía tres grandes pendientes colectivos en nuestro país, y que repensarnos como sociedad trasciende el mero ejercicio académico. Es un esfuerzo vital. Es la posibilidad de encontrar nuevos caminos y reafirmarnos en nuestra historia, en nuestro pasado, en nuestros relatos y vivencias personales. 